\title{
Governance of Nanotechnology: The case of regulation in European Union
}

\author{
${ }^{1,2}$ Ricardo Santana, ${ }^{3}$ Robin Zuluaga, ${ }^{4}$ Piedad Gañán \\ ${ }^{1}$ New Materials Group, Bolivarian Pontifical University, Medellín, Colombia. \\ ${ }^{2}$ Deustotech, University of Deusto, Bilbao, España. \\ ${ }^{3}$ Facultad de Ingeniería Agroindustrial, Universidad Pontificia Bolivariana, Circular $1^{\circ} \mathrm{N}^{\circ} 70-01$, Medellín, \\ Colombia. \\ ${ }^{4}$ Facultad de Ingeniería Química, Universidad Pontificia Bolivariana, Circular $1^{\circ} \mathrm{N}^{\circ} 70-01$, Medellín, \\ Colombia.
}

\begin{abstract}
European Regulation No 1223/2009, on cosmetic products presented the regulatory difference of nanomaterials over the rest of the chemicals for cosmetics. What has been the real impact of the standard after 10 years? It is concluded that this Regulation has encountered technical difficulties. This is the reason why objectives proposed by European Commission have not been accomplished.

\section{Types of Cosmetics}

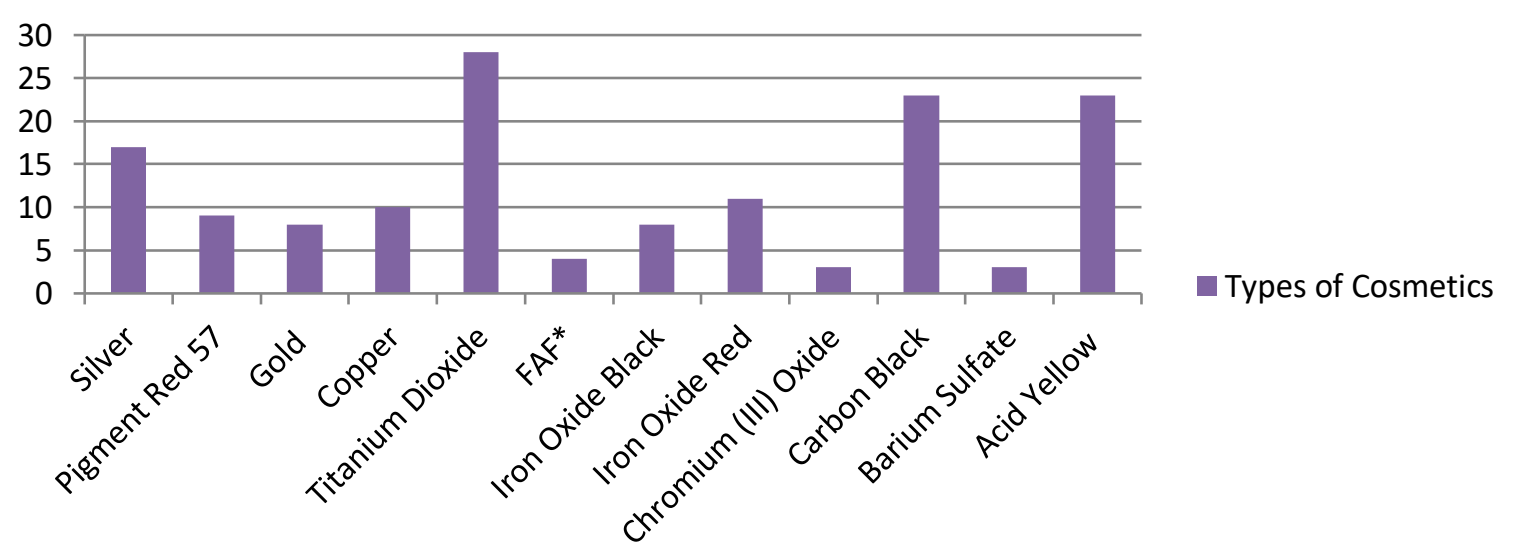

*FAF $=$ Ferric Ammonium Ferrocyanide

Fig. 1 Nanocolorants used in European Union in the different types of cosmetic products. Information based on the catalogue reported by the European Commission (Version 1 (31.12.2016))
\end{abstract}

1. European Commission (2012) Cosmetic Products Notification Portal. Article 13 User Manual. EC, Brussels. 
2. European Commission (2008) Commission Decision setting up an advisory structure of Scientific Committees and experts in the field of consumer safety, public health and the environment and repealing (No 721/EC (2008)). EC, Brussels.

3. European Commission (2012) User Manual for the Notification of Cosmetic Products Containing Nanomaterial according to article 16. EC, Brussels.

4. European Commission (2017) Catalogue of nanomaterials used in cosmetic products placed on the EU market. Version 1 (31.12.2016). EC, Brussels. 